\title{
Study on Computed Tomography Guided Fine Needle Aspiration Cytology of Peripheral Lung Lesions
}

\author{
Krishnendu Das ${ }^{1}$ \\ ${ }^{1}$ Assistant Professor, Department of Pathology, Malda Medical College, Malda, West Bengal, India.
}

\section{ABSTRACT}

\section{BACKGROUND}

Percutaneous transthoracic fine needle aspiration cytology (FNAC) under computed tomography is a well-established diagnostic method in the cytological evaluation of thoracic mass lesions. It plays an extremely vital role in small thoracic mass lesions $(<1 \mathrm{~cm})$ and deep mediastinal nodes in which needle placement is correctly possible by avoiding any surrounding blood vessel or cardiac structure. CT guided FNAC is an accurate \& sensitive way of diagnosing lung cancer. It also helps in staging of the malignancy. In addition, it helps in determination of the etiology of serious pneumonia when noninvasive methods have failed. We wanted to evaluate the role of Fine Needle Aspiration Cytology under Computed Tomography guidance in peripheral lung lesions.

\section{METHODS}

The study included 79 patients who presented with clinically suspected lung lesions in the Out-Patient Department, Department of Chest Medicine, Burdwan Medical College and Hospital in the period February 2009 to January 2010. A total of 79 patients who were either admitted or who attended the Chest Medicine OPD of Burdwan Medical College \& Hospital with suspected peripheral lung mass on chest $\mathrm{x}$ ray/CT scan. They were subjected to CT guided FNAC. Whenever possible, the cytological evaluations were compared with histopathological examination.

\section{RESULTS}

Definitive cytological diagnosis was obtained in 77 cases. Neoplastic lesions attributed to $92.4 \%$ of the cases. The sensitivity and specificity of the study were 97 $\%$ and $100 \%$ respectively.

\section{CONCLUSIONS}

CT guided Fine Needle Aspiration Cytology (FNAC) is a simple and safe procedure with high diagnostic accuracy for the diagnosis and cell typing of lung cancer at tertiary care centers. It is easy to perform in experienced hands, cost effective and less time consuming in comparison with surgical biopsy. Moreover, treatment decisions can be made based on the aspiration finding. In combination with clinical findings and radiological assistance in appropriate cases, high level of diagnostic outcome is achieved.

\section{KEY WORDS}

Computed Tomography, Fine Needle Aspiration Cytology, Peripheral Pulmonary Nodule or Masses
Corresponding Author:

Dr. Krishnendu Das,

Goaltuli Lane, P. O. Makdumpur,

Malda-732103,

West Bengal, India.

E-mail: drdas.krishnendu@gmail.com

DOI: $10.14260 / \mathrm{jemds} / 2019 / 539$

Financial or Other Competing Interests: None.

How to Cite This Article:

Das K. Study on computed tomography guided fine needle aspiration cytology of peripheral lung lesions. J. Evolution Med. Dent. Sci. 2019;8(31):2475-2479, DOI: 10.14260/jemds/2019/539

Submission 05-06-2019, Peer Review 15-07-2019, Acceptance 22-07-2019, Published 05-08-2019. 


\section{BACKGROUND}

Percutaneous transthoracic fine needle aspiration cytology (FNAC) is a well-established diagnostic method in the cytological evaluation of thoracic mass lesions for the last three decades. Although sporadic reports of the diagnosis of lung carcinoma by fine needle aspiration cytology appeared as early as 1886 (Menetrier),(1) the impetus for widespread use of the procedure only arose with the development of imaging techniques in late 1950's, allowing localization of small parenchymal lesions. It was Dahlgren \& Nordenstrom(2) in early 1960's who popularize the application of fluoroscopically guided transthoracic fine needle aspiration of lung masses. House AJ \& Thompson KR(3) in 1977 evaluated the efficacy of a new transthoracic biopsy needle (Rotex) under biplane fluoroscopy guidance with satisfactory outcome to diagnose benign \& malignant lung lesions. Knudsen DU et al

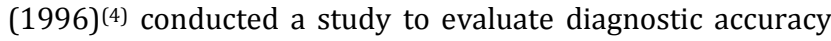
and complication frequency at ultrasonographically guided fine-needle aspiration biopsy of intrathoracic tumours with $93 \%$ accuracy. But with the advent of computed tomography (CT), guided FNAC was found safe, rapid and more accurate and highly effective for peripheral lung lesions.(5) Due to lack of direct visualization, the yield for bronchoscopic guided sampling especially of the small $<2 \mathrm{~cm}$ pulmonary nodules are very low. CT plays an extremely vital role in small thoracic mass lesions $(<1 \mathrm{~cm})$ and deep mediastinal nodes in which needle placement is correctly possible by avoiding any surrounding blood vessel or cardiac structure.(6) CT guided FNAC is an accurate \& sensitive way of diagnosing lung cancer.(7) It also helps in staging of the malignancy. In addition, it helps in determination of the aetiology of serious pneumonia when non-invasive methods have failed. The aim of the study is to evaluate the role of Fine Needle Aspiration Cytology under computed tomography guidance in peripheral lung lesions.

\section{METHODS}

The study included 79 patients presented with clinically suspected lung lesions in the out-patient department, Department of Chest Medicine, Burdwan Medical College and Hospital in the period of February 2009 to January 2010. The hilar or mediastinal lesions are excluded. Sample size was taken based on the convenience of the study.

The clinical history was taken, and each patient was examined in detail. The relevant points which were noted were recorded as per proforma. After obtaining written consent from the patient with exclusion of bleeding diathesis, FNAC of the lesion was done by following method.

After proper asepsis, aspiration was done using 21G, $20 \mathrm{cc}$ lumbar puncture needle through percutaneous and transthoracic approaches. The experienced radiologist identified the lesion in the exact section by CT scan. They measured the site of entry of the needle, route of the needle, and the distance between the skin and lesion on the CT scan monitor. After fixing adequately the $10 \mathrm{ml}$ syringe with the needle the aspiration was obtained and five to ten smears were prepared immediately from the sample. A follow-up CT scan was done in every patient immediately after the procedure to rule out pneumothorax. The slides were routinely stained with hematoxylin and eosin; Papanicolaou and May-Grünwald-Giemsa stains. The slides were studied and analyzed in terms of radiological, clinical and cytological data to reach a conclusive diagnosis. Histopathologic confirmation was done where possible. The study was approved by the Ethical Committee of the institution.

\section{Statistical Analysis}

The data was collected and analysed using standard statistical chi - square test, $\mathrm{P}<0.05$ statistically significant. Data was entered in Microsoft excel and analysis was done using SPSS version 22 .

\section{RESULTS}

Out of 79 cases involved in the present study, 66 (83.5\%) were male \& $13(16.5 \%)$ were female. The age range in this study population was 18-85 years with both youngest \& oldest persons were male; the overall mean age of all the patients was 56.6 years with standard deviation 10.4. A gender wise examination of the patient's ages revealed that the mean age was 58.2 years for the males and 54.9 years for the females. Interestingly, lung malignancy was found most frequently $(32.9 \%)$ in the age group 61-70 years amongst the male \& equal number of cases were seen in the age range $41-50$ years and 51-60 years amongst the female. In terms of clinical manifestations, cough is the most common mode of presentation $(70.7 \%)$ followed by chest pain, respiratory distress, weight loss. Less frequently found clinical features are haemoptysis, fever, clubbing, backache etc. 5 cases were associated with pleural effusion \& 4 cases with collapse of lung. 4 cases were found to have superior venacaval syndrome. On CT scan 3 cases were found to be associated with rib erosion. Smokers were clearly predominant $(55.7 \%)$ over nonsmokers in terms of lung lesions.

All the pulmonary masses were peripheral parenchymal lesions. No hilar lesions were considered to be included in the study. Out of 79 cases, $41(51.9 \%)$ were in the right side \& $38(48.1 \%)$ cases were in the left side of lung. Majority of pulmonary lesions were situated posteriorly 51 cases $(64.6 \%)$ while other sites were anteriorly $21(26.6 \%)$, middle $5(6.3 \%)$ $\&$ diffuse $2(2.5 \%)$. Among the 79 cases, 38 cases $(48.1 \%)$ were in the mid zone, followed by 27 cases (34.2\%) in the upper zone, 12 cases $(15.2 \%)$ in the lower zone. Two huge tumours $(2.5 \%)$ involved the entire lung field.

According to the CT findings, the size of the lesions varied from 1.6 to 14.1 centimeter in diameter. Only 15 cases (18.9\%) were $<5 \mathrm{~cm}$ in diameter \& amongst them 5 cases were $<2.5 \mathrm{~cm}$ which were difficult to access. The size 60 lesions varied from 5.2 to $10 \mathrm{~cm}$ whereas 4 cases were very big $(>10 \mathrm{~cm}$ in diameter). Out of 79 cases of thoracic mass lesions, definitive cytological diagnosis was obtained in 76 cases and 3 cases were unsatisfactory. Amongst the latter, one lesion was subsequently diagnosed as sarcomatoid carcinoma by tru-cut needle biopsy \& one patient underwent bronchoscopic biopsy that was on suspicion due to positive sputum cytology. 


\begin{tabular}{|c|c|c|}
\hline $\begin{array}{c}\text { Anatomical Location of the Lesion } \\
\text { (CT Scan Finding) }\end{array}$ & No. of Cases & Percentage (\%) \\
\hline Anterior & 21 & $26.6 \%$ \\
\hline Posterior & 51 & $64.6 \%$ \\
\hline Middle & 05 & $6.3 \%$ \\
\hline Diffuse & 02 & $2.5 \%$ \\
\hline Table 1. Distribution of Pulmonary Lesions according to Anatomical \\
Location (Total No. 79) \\
\hline
\end{tabular}

\begin{tabular}{|c|c|c|}
\hline Anatomical Location of the Lesion & No. of Cases & Percentage (\%) \\
\hline Upper zone & 27 & $34.2 \%$ \\
\hline Mid zone & 38 & $48.1 \%$ \\
\hline Lower zone & 12 & $15.2 \%$ \\
\hline Diffuse & 02 & $2.5 \%$ \\
\hline Total & $\mathbf{7 9}$ & $\mathbf{1 0 0}$ \\
\hline
\end{tabular}

Table 2. Distribution of Pulmonary Lesions According to Anatomical Location (Total No: 79)

\begin{tabular}{|c|c|c|}
\hline Nature of the Lesion & No. of Cases & Percentage (\%) \\
\hline Malignant neoplasm & 73 & $92.4 \%$ \\
\hline Benign neoplasm & 01 & $1.3 \%$ \\
\hline Inflammatory/granulomatous & 03 & $3.8 \%$ \\
\hline Atypical & 00 & $0 \%$ \\
\hline Unsatisfactory & 03 & $3.8 \%$ \\
\hline $\begin{array}{r}\text { Table 3. Distributic } \\
\text { The Natu }\end{array}$ & sions (Totc & $\begin{array}{l}\text { According to } \\
\text { 9) }\end{array}$ \\
\hline
\end{tabular}

\begin{tabular}{|c|c|c|}
\hline Type of Lung Tumour & No. of Cases & $\begin{array}{l}\text { Percentage }(\%) \\
\text { Out of } 79 \text { Cases }\end{array}$ \\
\hline Squamous cell carcinoma & 30 & $38.0 \%$ \\
\hline Adenocarcinoma & 31 & $39.2 \%$ \\
\hline Small cell carcinoma & 06 & $7.6 \%$ \\
\hline Large cell carcinoma & 01 & $1.3 \%$ \\
\hline Undifferentiated carcinoma & 03 & $3.8 \%$ \\
\hline Sarcomatoid carcinoma & 01 & $1.3 \%$ \\
\hline Secondary malignancy & 01 & $1.3 \%$ \\
\hline \multicolumn{3}{|c|}{$\begin{array}{l}\text { Table 4. Distribution of Malignant Tumours of Lung as Diagnosed by } \\
\text { Cytological Examination (Adopted from WHO Classification 1999)(16 } \\
\text { (Total No: 73) }\end{array}$} \\
\hline
\end{tabular}
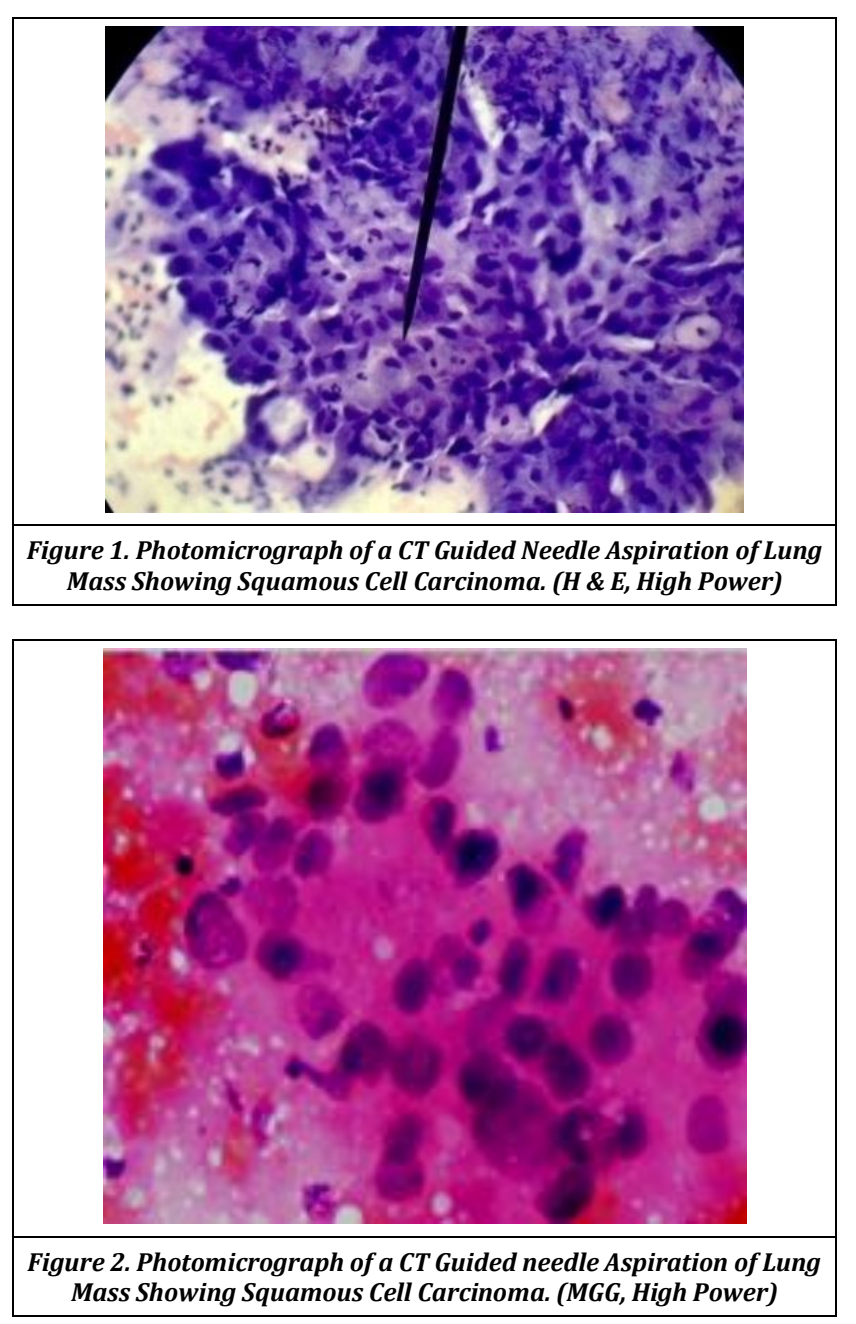

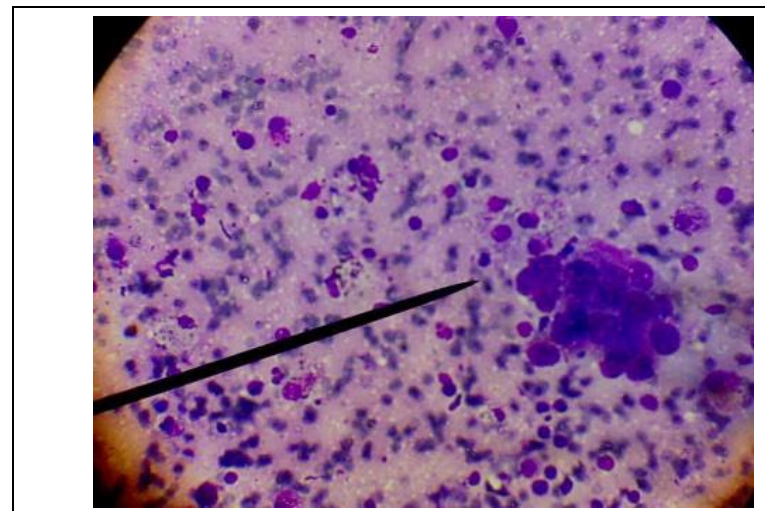

Figure 3. Photomicrograph of Lung Showing Adenocarcinoma with Numerous Carbon Laden Macrophages (Giemsa, High Power)

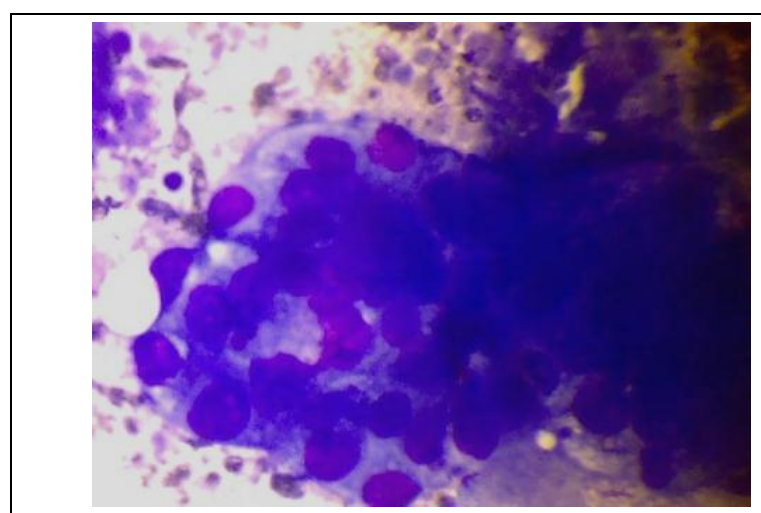

Figure 4. Photomicrograph of Lung-Adenocarcinoma Cell Ball (May-Grunwald-Giemsa, High Power)

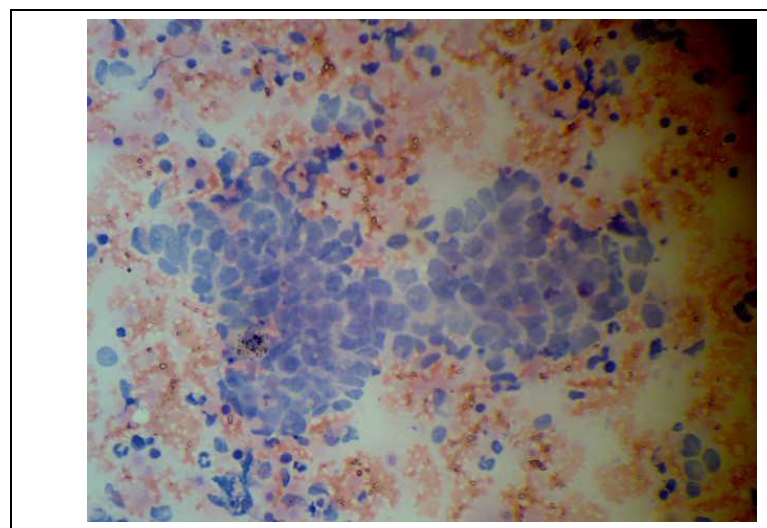

Figure 5. Photomicrograph of Lung Showing Small Cell Carcinoma with no Cytoplasm and Nuclear Moulding (H \& E, High Power)

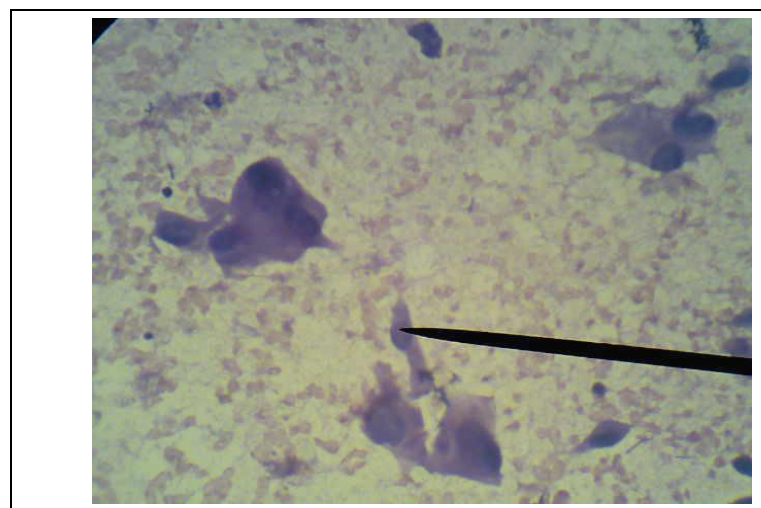

Figure 6. Photomicrograph of Lung Showing Anaplastic Large Cell Carcinoma Having Dispersed Large Pleomorphic Cells with Abundant Cytoplasm (H\&E, High Power) 
In the present study, it was found that neoplastic lesions $(92.4 \%)$ had clearly outnumbered the non-neoplastic lesions. Almost all the neoplastic lesions were found to be malignant except one case where we had a hamartoma simultaneously co-existent with a squamous cell carcinoma. All the inflammatory conditions were diagnosed as tubercular granuloma. Out of 73 malignant lung tumours in our study, it was found that adenocarcinomas had a slight edge (39.2\%) over squamous cell carcinoma (38\%). 3 cases were diagnosed as undifferentiated carcinoma due to lack of definitive cytologic evidence of either squamous/adeno/small cell. One case was diagnosed as sarcomatoid carcinoma on tru-cut biopsy due to inconclusive FNA cytology. Only one metastatic lung tumour was diagnosed in a known case of osteosarcoma where we obtained cellular smears having poorly cohesive spindle shaped cells with fragile cytoplasm, bizarre nuclei with dense chromatin and small inconspicuous nucleoli and occasional bizarre multinucleated giant cell.

\section{DISCUSSION}

Fine needle aspiration cytology under radiological guidance is widely becoming a practical means of obtaining a definitive diagnosis of pulmonary lesions since procedures like nondiagnostic exfoliative cytologic studies \& bronchoscopic biopsy or lavage has restricted utility for diagnostic purposes.

Computed tomography guided aspiration is relatively inexpensive, associated with high reliability, minimal patient discomfort, and few and relatively minor complications.

In the present study, all the 79 patients are found adults with the peak age incidence (61-70 years) is somewhat older than that documented in recent studies by Saha et al (2009) in 57 cases, Shah et al (2007) in 100 cases (2009)(5)(7) but similar to that conducted by Basnet et al (2008)(11). However, the mean age (56.6 years) is almost similar (56.8 years) \& (56.4years) to the studies conducted by Saha et al(5) and Singh et al(8) respectively which were slightly lower (mean age 61.3 years) than that shown by Wallace et al ${ }^{(6)}$ in cases of small $(<1$ $\mathrm{cm})$ pulmonary lesions. Male patients (85.3\%) shows significant preponderance in our study compared to females $(14.7 \%)$. Saha et al $(78.9 \%)^{(5)}$, Shah et al $(88 \%)^{(7)}$, Bandyopadhyay et al $(80.6 \%)^{(9)}$ etc Singh et al(8), Wallace et $\mathrm{al}^{(6)} \& \mathrm{~KB}$ Tan et al(10) showed a significant lower incidence of male patients i.e $52 \%, 55.7 \%$ \& $71.1 \%$ respectively.

In this study, lung tumours are found located more in the right side (52\%) than in the left. Saha et al(1) \& Basnet et al(11) also found similar results. zone-wise distribution of lung tumours on the basis of CT scan findings and found that the mid zone $(48 \%)$ is the most common site followed by the upper zone in contrast to the study by Saha et al(5) \& Behara et al(12) that upper zone was the most frequent side.

The lesions are quite large in our series: the majority of the thoracic mass lesions (60 out of 79 cases) were $5-10 \mathrm{~cm}$ in diameter. The pulmonary mass lesions were more variably sized $(1.6-14.1 \mathrm{~cm})$ similar to the study by Saha et al but unlike to Singh et al $(1.2-5.6 \mathrm{~cm})$.

Consistent with findings from study by Singh et al \& Saha et al, we observed a notable correlation of complications with the distance of the pleura from the lesion. All complications were seen where the lesions were the furthest, i.e., 5-6 cm away from the pleura. The overall rate of complications in our study was also remarkably less than other series where the range varied from six to $50 \%$. (5),(8),(9),(10),(13) This was thought to be due to the larger size of the tumour masses in our series and also due to our meticulous and proper aspiration procedure.

Cytological diagnosis was made in 74 out of 79 cases $(93.7 \%)$ and from the rest of the 5 cases where sampling was inadequate 2 cases have been diagnosed properly by subsequent biopsy. Of the 76 diagnosed cases (including those confirmed by biopsy) incidence of malignancy (92.4\%) was found prevalent over benign conditions (5\%). The results are comparable with that of others i.e Saha et al (96.5\%)(5), Basnet et al $(62 \%)^{(12)}$, Bandyopadhyay et al $(67.9 \%)^{(9)}$, Singh et al $(81.8 \%)^{(8)}$ etc. Of all the cases of primary lung malignancies, adenocarcinoma was found most commonly ( $n=31 ; 39.2 \%)$ followed by squamous cell study are undifferentiated carcinoma (3 cases, $3.8 \%$ ), large cell carcinoma (1 case, $1.3 \%$ ), sarcomatoid carcinoma (1 case, 1.3\%). These findings are clearly in contrast with results reported by Saha et al, Bandyopadhyay et al, Basnet et al where squamous cell carcinoma was prevalent (42.6\%, 28.9\%, 27\% respectively). On the contrary, Tan et al(10) found higher incidence adenocarcinoma in their work.

The prevalence of squamous cell carcinoma and adenocarcinoma were similar (22\%) in the study by Singh et al (2004) but studies by Guoliamos (2000)(14) \& Rajwanshi (1989)(15) found relatively higher percentage of large cell carcinomas. D. Behara \& T. Balamugesh in their 'Lung cancer in India' article figured higher incidence of squamous cell carcinoma (34.6\%) and an interestingly significant percentage of anaplastic carcinomas (27.6\%). In our study, poorly differentiated carcinoma (including undifferentiated \& sarcomatoid ones) were prevalent over large cell carcinoma clearly in contrast with Saha et al where both were equally prevalent (3.7\% each).

Only one metastatic tumour was found in our study where the primary was an osteosarcoma involving left lower limb contrasting to that of Saha et al. Bandyopadhyay et al found 3 cases of secondary malignancy

Of all the benign lesions (4) we found, 3 cases were diagnosed as granulomatous inflammation consistent with tuberculosis. One case was diagnosed as hamartoma which was co-existent with a case of squamous cell carcinoma.

WHO classification of 1999 was adopted while describing the prevalence of lung tumours, but for practical purposes the classification into small cell and non-small cell categories is often satisfactory and often accomplished in majority of the cases.

\section{CONCLUSIONS}

CT guided fine needle aspiration cytology (FNAC) is a simple and safe procedure with high diagnostic accuracy for the diagnosis and cell typing of lung cancer at tertiary care centers where ultrasound guided biopsy is not feasible. The procedure enables the clinician to obtain a definitive diagnosis in a high percentage of patients at an affordable cost in a short span of time. It is easy to perform in experienced hands, cost effective and less time consuming in comparison with surgical biopsy. Moreover, treatment decisions can be made based on this aspiration finding. In combination with clinical findings and 
radiological assistance in appropriate cases, high level of diagnostic outcome can be achieved.

\section{REFERENCES}

[1] Menetrier, P Cancer primitif du poumon. Bull Soc Anat Paris. 1886;11:643-647.

[2] Dahlgren S E: Aspiration biopsy of intrathoracic tumours. Acta Pathol Microbiol Scand. 1967;70:566-576.

[3] House AJ, Thomson KR. Evaluation of a new transthoracic needle for biopsy of benign and malignant lung lesions. AJR Am J Roentgenol. 1977 Aug;129(2):215-220.

[4] Knudsen DU, Nielsen SM, Hariri J, Christensen J, Kristensen S. Ultrasonographically guided fine-needle aspiration biopsy of intrathoracic tumours. Acta Radiol. 1996 May;37(3 Pt 1):327-331.

[5] Saha A, Kumar K, Choudhuri MK. Computed tomographyguided fine needle aspiration cytology of thoracic mass lesions: A study of 57 cases. J Cytol 2009;26(2):55-59.

[6] Wallace MJ, Krishnamurthy S, Broemeling LD et al. CT guided percutaneous fine needle aspiration biopsy of small $(\leq 1 \mathrm{~cm})$ pulmonary lesions. Radiology 2002;225:823-8.

[7] Shah S, Shukla K, Patel P. Role of fine needle aspiration cytology in diagnosis of lung tumours. A study of 100 cases. Indian J Pathol Microbiol 2007;50:56-8.

[8] Sing JP. Garg L, Setia V. Compared tomography (CT) guided transthoracic needle aspiration cytology in difficult thoracic mass lesions - not approachable by USG. Indian J Radiol Imaging 2004;14:395-400.
[9] Bandyopadhyay A, Laha R, Das TK, Sen S, Mangal S, Mitra PK. CT guided fine needle aspiration cytology of thoracic mass lesions: A prospective study of immediate cytological evaluation. Indian $\mathrm{J}$ Pathol Microbiol 2007;50:51-5.

[10] Tan KB, Thamboo TP, Wang SC, Nilsson B, Rajwanshi A, Salto-Tellez M. Audit of transthoracic fine needle aspiration of the lung: Cytological subclassification of bronchogenic carcinomas and diagnosis of tuberculosis. Singapore Med J 2002;43:570-5.

[11] Basnet SB, Thapa GB, Shahi R, Shrestha M, Panth R. Computed tomography guided percutaneous fine needle aspiration cytology in chest masses. JNMA Jul-Sep 2008;47(3):171.

[12] Behara D, Balamugesh T. Lung cancer in India. Indian J Chest Dis Allied Sci 2004;46:269-281.

[13] Mullan CP, Kelly BE, Ellis PK, Hughes S, Anderson N, McCluggage WG. CT-guided fine-needle aspiration of lung nodules: Effect on outcome of using coaxial technique and immediate cytological evaluation. Ulster Med J 2004;73:32-6

[14] Gouliamos AD, Giannopoulos DH, Panagi GM, Fletoridis NK, Deligeorgi-Politi HA, Vlahos LJ. Computed tomography-guided fine needle aspiration of peripheral lung opacities: An initial diagnostic procedure? Acta cytological 2000;44(3):344-8.

[15] Rajwanshi A, Jayaram N, Behera D, Gupta SK, Malik SK. Fine needle aspiration of intrathoracic lesions. Indian J Pathol Microbiol 1989;4:306-9.

[16] Travis WD, Colby TV, Corrin B, et al. WHO histologic typing of lung and pleural tumours, $3^{\text {rd }}$ ed. Geneva: World Health Organization, 1999. 